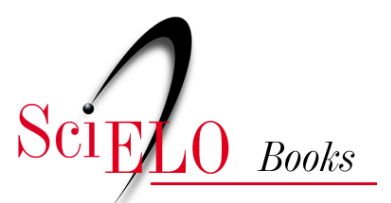

\title{
Introdução \\ a construção de uma composição polifônica sobre um tema principal - categorias sêmicas em síndrome de Down
}

\author{
Ana Cristina Bohrer Gilbert
}

\section{SciELO Books / SciELO Livros / SciELO Libros}

GILBERT, A.C.B. Introdução: a construção de uma composição polifônica sobre um tema principal categorias sêmicas em síndrome de Down. In: Vértice do impensável: um estudo de narrativas em síndrome de Down [online]. Rio de Janeiro: Editora FIOCRUZ, 2012, pp. 27-40. Criança, mulher e saúde collection. ISBN: 978-85-7541-572-6. https://doi.org/10.7476/9788575415726.0003. \section{International license.}

All the contents of this work, except where otherwise noted, is licensed under a Creative Commons Attribution 4.0

Todo o conteúdo deste trabalho, exceto quando houver ressalva, é publicado sob a licença Creative Commons Atribição 4.0. 


\section{INTRODUCÃO \\ A CONSTRUÇ̃̃O DE UMA COMPOSIÇÃO POLIFÔNICA SOBRE UM TEMA PRINCIPAL - CATEGORIAS SÊMICAS EM SÍNDROME DE DOWN}

A construção de uma fuga requer determinadas regras, visando a alcançar o resultado desejado, isto é, uma composição rica em variações, agradável não apenas aos sentidos, mas também à imaginação. Da mesma forma, uma pesquisa resulta de um estudo organizado segundo critérios ou regras, empreendido durante alguns - às vezes muitos - anos. $\mathrm{E}$ para contá-la é preciso dar a conhecer ao leitor o caminho trilhado e os alicerces sobre os quais ela foi construída.

Quando se decide contar uma história, a primeira questão que surge é sobre o ponto de partida. Por onde começar? Onde essa história começa?

Pode-se dizer que começa com o interesse da autora, psicóloga de formação, pelas palavras e pelas imagens e a forma como elas se entrelaçam e se definem umas às outras. Começa também na perspectiva clínica do lidar com o humano, que sempre pautou a sua prática profissional. E atrelado ao interesse e à perspectiva clínica, com a curiosidade sobre a permeabilidade das fronteiras entre os círculos biomédico/científico e o considerado como leigo, e a maneira como as informações produzidas no primeiro são divulgadas e transformadas por meio de códigos culturais compartilhados que servem como mediadores entre a produção e a recepção de mensagens.

Mas, em outra perspectiva, o início dessa história deixa de ser início porque retoma um fio deixado por uma outra história, conforme já dito, que faz vibrar profundamente inquietações quanto aos rumos de um movimento que envolve, mas também aprisiona pessoas com síndrome de Down (SD). 
Este livro analisa as imagens culturalmente produzidas que são veiculadas nas narrativas escritas e iconográficas sobre SD e discute como a presença de uma condição geneticamente determinada torna-se fator estruturante de identidade. Usa-se o termo imagem num sentido bastante amplo, referindo-se não apenas às representações figuradas em si, mas a tudo o que é transmitido por estas e por palavras, compondo significados. Considera-se que a produção cultural sobre SD revela imagens e significados que refletem a maneira como a sociedade se relaciona com pessoas que trazem a marca dessa condição genética particular, articulada àquilo que é convencionado como padrão de normal e patológico, de 'mesmo' e de 'outro', com base no discurso biomédico. $\mathrm{O}$ interesse, pois, em pesquisar as narrativas sobre SD refere-se não à identificação de entendimentos errôneos sobre o assunto com a intenção de corrigi-los, mas à interseção entre os conhecimentos biomédico e leigo para moldar significados sobre a SD.

Para tanto, trabalhou-se com o conceito expandido de etnografia proposto por Donna Haraway (1997), o qual extrapola aquele referente a um tipo de procedimento usado em antropologia, que a define como um método assentado na perspectiva de conhecimentos localizados, enfoques parciais, contextualizados e críticos, com múltiplas possibilidades de conexões, e que implica se colocar em risco em face das práticas e dos discursos sobre os quais se questiona. Estar em risco não significa se identificar com os sujeitos de estudo, tampouco autoidentificar-se, quer dizer, centrarse em suas próprias convicções e fazer julgamentos. É estar diante daquilo que não é identificável e que desafia estabilidades, certezas e maneiras de ser, com um modo de atenção ao mesmo tempo prático e teórico, consciente e responsável, tendo-se claro que se está lidando com propósitos e expectativas próprios e dos outros.

Assim, apesar de este livro não consistir num trabalho etnográfico tradicional, uma vez que a análise centra-se na produção cultural difundida por diferentes meios de comunicação e não no contato direto com pessoas com SD e seus familiares, ocorreu uma imersão na realidade apresentada nas narrativas, igualmente arriscada e desestabilizadora, como 
bem o postula Haraway, por tratar mais com questões do que com respostas, por buscar nas próprias narrativas aquilo que é importante perguntar.

Quem narra alguma coisa está contando uma história, independentemente do meio que utiliza para fazê-lo: pode ser uma narrativa oral, escrita, cinematográfica ou pictórica. Tradicionalmente, a narrativa é considerada como a expressão de um comportamento humano que é ao mesmo tempo imitativo e representativo, serve à comunicação entre as pessoas e veicula sentidos, entendidos aqui como significação ou significado não cristalizado, mas também como algo que implica intencionalidade e finalidade (Cardoso, 1997).

Devido ao interesse em analisar e compreender a realidade, considerando-a como algo que é dependente da interpretação humana, acessada por meio dos conteúdos explícito e implícito das narrativas sobre SD, optou-se por situar a análise das fontes no âmbito da semiótica, um campo que envolve diferentes perspectivas teóricas e ferramentas metodológicas e que pode ser definido de forma ampla como o estudo dos signos.

Para o filósofo americano Charles Sanders Peirce (2003: 46), um signo é "aquilo que, sob certo aspecto ou modo, representa algo para alguém". Signos englobam palavras, imagens, sons, objetos, atitudes, enfim, qualquer elemento que, apesar de não possuir significado em si, possa ser investido de significado por alguém (Chandler, 2007).

Para Peirce (2003), o modelo de signo é triádico, consistindo num representâmen, que é a forma (não necessariamente material) que o signo toma, isto é, aquilo que representa algo para alguém; um 'interpretante', que é o signo que foi criado na mente desse alguém a partir do representâmen; e o 'objeto' ou 'referente', aquilo no lugar do qual o signo está. Logo, para ser considerado um signo, os três elementos devem estar presentes: aquilo que é representado, como ele é representado e como ele é interpretado por alguém. De acordo com a forma de relação estabelecida entre o representâmen e o interpretante, os signos podem ser índices (quando existe uma conexão direta entre os dois), ícones (quando ambos se assemelham) ou símbolos (quando a relação é baseada numa convenção). 
Em semiótica, nada é completamente neutro, sendo impossível representar algo exatamente como é. O uso da linguagem vai além do simples nomear de coisas, as quais não são independentes dos sistemas de signos usados pelos grupos humanos. Palavras são abstrações, e nem todas correspondem a objetos materiais no mundo. Conforme aponta Michel Foucault (2002), a partir do século XVII rompe-se o parentesco por similitude, a conexão considerada como 'natural' entre as palavras e as coisas: as palavras deixam de ser os nomes das coisas para ser sua representação.

O famoso quadro do pintor surrealista belga René Magritte La Trahison des Images [A Traição das Imagens], de 1926, o qual mostra uma representação de um cachimbo visto de lado e, abaixo dele, a inscrição Ceci n'est pas une pipe [Este não é um cachimbo], ilustra a noção de que qualquer representação é mais do que uma simples reprodução daquilo que pretende representar, e que contribui em certo sentido para a construção da realidade (Foucault, 1983). Tal como as palavras são representações, também as imagens não podem ser confundidas com o objeto ao qual se referem. Dito de outra forma, a presença da imagem afirma a ausência do objeto ao qual alude.

Ao se analisarem as relações estruturais subjacentes a textos e práticas culturais, cabe ressaltar a importância de não se subestimarem os sistemas sociais que as sustentam. Não se trata de considerar apenas a relação entre os elementos de um texto, mas também os significados atribuídos pelos leitores aos signos nele presentes.

Significados não são dados ou transmitidos de forma pronta, mas criados em consonância com as inter-relações existentes entre os códigos e as convenções de um grupo, muitas vezes despercebidos pelos seus membros. O processo de explicitar de que maneira os signos são interpretados, e dentro de que sistema de códigos, permite contestar aspectos da realidade tidos como 'naturais' e entender o sentido de sua existência.

O uso de tropos contribui para tornar o estranho familiar; o uso repetido de determinadas figuras de linguagem traduz um acordo subliminar que se faz como membro de um grupo, no qual determinadas 
afirmações são compartilhadas e entendidas como verdadeiras. Imagens comunicam pelos elementos nelas presentes (ou ausentes) e pela relação entre eles e, principalmente, são percebidas de acordo com a perspectiva daquele que observa, não podendo seu conteúdo simplesmente ser assumido como universal.

A fotografia, em especial, suscita um velho e inesgotável debate sobre o quanto ela é uma fiel reprodução do 'real'. Em primeiro lugar, está o fato de que a fotografia é uma representação bidimensional de um mundo que é tridimensional - o que por si só já destitui o caráter de fidelidade ao real. Em segundo lugar, sabe-se que qualquer fotografia resulta de uma série de opções feitas pelo fotógrafo no momento em que fotografa, como composição, enquadramento e iluminação, por exemplo, e outras tantas opções feitas após o disparo e que dizem respeito à edição da imagem, obtida tradicional ou digitalmente, como corte, ajuste de contraste e balanço de cor, só para citar algumas.

Toda imagem carrega em si uma mensagem conotativa, não apenas por todo o seu processamento, mas também por se referir a como a sociedade, na qual essa imagem circula, entende e comunica determinado aspecto da realidade. Entretanto, nem sempre a conotação é clara e explícita; ela pode ser apreendida nos fenômenos que envolvem a produção e a recepção da mensagem (Barthes, 1977). Implícitas a cada imagem, outras ainda se escondem, numa rede de analogias, correspondências e confrontações. Contudo, a forma como determinadas imagens são conectadas a significados particulares para veicular mensagens específicas, delas extraindo-se o seu conteúdo histórico e contextual, constitui um fenômeno social que Roland Barthes (2001) definiu como a criação de um mito, e que traduz formas de pensar sobre pessoas, ideias, produtos ou lugares. Não é o objeto em si que se torna mito, mas o modo como é proferido. O fato de a fotografia ser uma reprodução, capturada mecanicamente, daquilo que se encontra em frente à câmera leva a crer que ela não está sujeita a nenhum tipo de código. Contudo, tal fato revela-se como um de seus aspectos míticos e serve de base para a atuação de códigos culturais na produção de significados. 
As sequências exibidas em filmes pautam-se por códigos cinematográficos compartilhados pelo cineasta e pela audiência, os quais ditam a forma como os signos (gráficos, sonoros, fotográficos e linguísticos) são combinados e utilizados para gerar significados (Bignell, 2002). Segundo Umberto Eco (1979), os sistemas de códigos, necessários ao processo de significação das imagens, não estabelecem significados específicos para cada elemento de um texto, mas sim as bases para a compreensão de todo o processo textual. A decodificação dos signos por parte do espectador é um processo ativo; assim, os significados são construídos não pela leitura de um significado específico que se apresenta 'pronto' no texto, mas por meio de uma verificação e de um ajuste contínuos desses códigos por parte do espectador.

Reportagens não são apenas fatos, mas representações da realidade produzidas com a utilização de diferentes tipos de signos, como os linguísticos e os visuais, por profissionais com determinada orientação de pensamento, composição e escrita para cada tipo de discurso da mídia impressa. As conotações incorporadas a tais signos moldam significados por meio de códigos jornalísticos que o leitor reconhece como familiares. O que se entende por jornalismo científico, ao qual se costuma associar qualidades como neutralidade, objetividade e verdade, também é submetido aos mesmos códigos e resulta de um processo que nada tem de 'natural' ou puramente denotativo.

Por conseguinte, ao se analisarem imagens apresentadas em campanhas, filmes, livros, blogs ou reportagens, entende-se que elas não são meramente apêndices do texto, mas dotadas de autonomia estrutural sem ser, contudo, dele dissociadas. Palavras, no caso do texto, e linhas, sombras e superfícies, no caso das imagens (individuais ou sequências), compõem substâncias diferentes (Barthes, 1977, 2003) que são analisadas em separado e, a seguir, de forma complementar.

As fontes analisadas referem-se à produção cultural sobre SD voltada para o público em geral. Delas foram excluídas aquelas produzidas no círculo biomédico e endereçadas ao público especializado, apesar de também se constituírem como produtos da cultura. ${ }^{1}$ Não se pretendeu 
esgotar tal repertório, mas trabalhar com o que se apresentou como relevante, narrativa sugerindo narrativa, numa sequência de indícios capturados ao longo do trajeto. Essas fontes são descritas a seguir, organizadas em três grupos principais.

O primeiro grupo é composto por imagens plurais, narrativas que estavam em evidência na mídia impressa e televisiva, em publicações voltadas para o público em geral e no cinema durante o curso da pesquisa. $\mathrm{O}$ slogan "Ser diferente é normal", das campanhas publicitárias criadas pela agência de publicidade Giovanni FCB para o Instituto MetaSocial e veiculadas em 2003, 2004, 2005 e 2008, teve grande repercussão e transformou a SD em símbolo do movimento de inclusão da diversidade humana. É analisado com a fotografia a ele associada em 2003 e 2004, por ser esse momento um importante marco na atuação do instituto em termos de ampliação do seu alcance. O Instituto MetaSocial é uma organização não governamental sem fins lucrativos, criado por um grupo de pais e amigos e formalizado em 2004, visando à inclusão de pessoas com deficiência. Trabalha com projetos ligados à informação, tendo participado de diversas campanhas veiculadas pela mídia com o objetivo de informar sobre potencialidades e capacidades dessas pessoas.

A pintura de Andrea Mantegna (1431-1506) que representa a Virgem com o Menino Jesus, Madonna col Bambino, é conhecida e assumida como representando uma criança com SD, tanto no círculo biomédico quanto no não especializado, sendo divulgada em livros, sites e blogs em diversos idiomas, com disseminação dos significados por ela sugeridos. O pintor renascentista, extremamente minucioso no tocante à representação do que via, teve algumas de suas obras estudadas em razão da sua possível relação com a SD (Stratford, 1982, 1996; Schwartzman, 1999; Cardoso, 2000; Pueschel, 2005). Pintor oficial da poderosa família Gonzaga de Mantua, Mantegna foi um dos primeiros artistas a utilizar modelos vivos para suas pinturas. Tais estudos sugerem que os modelos usados nesse quadro são uma criança e sua mãe, Barbara di Brandeburgo, da família de seu patrono, ou a própria esposa de Mantegna, ou uma de suas amantes e seu filho. Segundo foi investigado, as duas crianças tinham a mesma doença, e os 
sinais descritos apontam para a SD; nesse quadro observa-se, principalmente, a hipotonia do bebê e o bócio na mulher, indicando uma disfunção da tireoide, por muito tempo associada às crianças afetadas.

O documentário brasileiro de 2004 Do Luto à Luta, com roteiro e direção de Evaldo Mocarzel e produzido por Casa Azul Produções Artísticas e Circuito Espaço de Cinema, foi exibido no $2^{\circ}$ Festival Internacional de Filmes sobre Deficiência Assim Vivemos, patrocinado pelo Centro Cultural Banco do Brasil (CCBB), edição 2005. Ganhou o Prêmio Especial do Júri no Festival de Gramado, o de Melhor Documentário - Júri Popular no Festival do Rio - e mais sete prêmios no Cine PE, em 2005. O filme conta a história de várias famílias, entre elas a do próprio diretor, e o processo vivido por elas a partir do diagnóstico de SD até o presente. Dele foi retirada uma imagem utilizada na capa do vídeo e na sua divulgação, representando um casal com SD, e que resume um dos principais questionamentos sobre o futuro dessas pessoas. Por ocasião do lançamento do filme, o diretor e o casal foram entrevistados pela jornalista Marília Gabriela em seu programa Marília Gabriela Entrevista, no canal por assinatura GNT/Globosat. Uma pergunta feita pela entrevistadora foi escolhida para análise por se conectar à narrativa anterior.

O segundo grupo é composto por 164 narrativas na forma de relatos em livros, coletivos e individuais, e 352 na forma de blogs de acesso livre, escritos e produzidos por pais de pessoas com SD, nos idiomas português, inglês e espanhol.

A princípio, intencionava-se centrar a análise nas fontes extraídas do panorama brasileiro. Entretanto, dois fatores foram decisivos na modificação da ideia inicial: o primeiro deles, o número restrito de livros produzidos no Brasil, despertando a curiosidade com relação a essa produção em outros países para comparar significados. O segundo refere-se à falta de restrição espacial proporcionada pela Internet, eliminando distâncias e exacerbando a proximidade temporal das narrativas. Disso resulta a demarcação de um território que não é da ordem do geográfico, mas da identidade biológica, o território da SD. Em muitos blogs, a completa ausência de 'enraizamento' levou a uma leitura dos sinais que dessem pistas sobre 
esse dado, uma vez que era de interesse localizar as narrativas para analisálas, a fim de não se desprezarem possíveis diferenças culturais.

As publicações, selecionadas por meio de busca on-line nas livrarias virtuais Cultura e Amazon, são majoritariamente dos Estados Unidos, sendo que oito narrativas na forma de livro foram produzidas no Brasil e apenas uma na Espanha. Se comparada à dos Estados Unidos, a publicação nacional é escassa, bem como é escasso o contato da maioria das pessoas com o material publicado.

Os blogs foram selecionados com base na busca on-line e por meio das indicações presentes em cada um deles, compondo uma espécie de rede. Foram acessados entre novembro de 2008 e março de 2009. Incluem produções dos Estados Unidos (a maioria), Brasil, Chile, Colômbia, Costa Rica, Argentina, Guatemala, Canadá, Espanha, Áustria, Reino Unido, Irlanda, África do Sul, Austrália, Arábia Saudita e Israel. Os blogs brasileiros organizados em grupos fechados, como grupos de discussão aos quais só se tem acesso mediante inscrição e que constituem maioria, não foram considerados na análise. Esse tipo de organização, na qual as trocas de experiências são restritas a um território específico, se por um lado cria um ambiente protegido e controlado para recontar histórias consideradas difíceis e remodelar identidades, por outro 'destaca' o território da SD no sentido etimológico apresentado pelo Dicionário Houaiss (Houaiss, Villar \& Mello Franco, 2004: 1.017), cuja origem remonta ao latim destaccare (retirar, separar).

A realidade apresentada nos blogs produzidos nos Estados Unidos é bastante diversa da que se observa em países como o Brasil, onde tais pessoas dependem quase que exclusivamente de suas famílias (particularmente os pais), e o acesso a trabalhos diferenciados que auxiliem no seu desenvolvimento é restrito a uma minoria. A sociedade americana valoriza enormemente ações comunitárias: um grande número de instituições financia a publicação de livros sobre a questão da deficiência, não apenas a SD, além de oferecer uma extensa rede de apoio a essas pessoas. ${ }^{2} \mathrm{O}$ aprendizado da linguagem de sinais é parte fundamental desse processo, criando canais de expressão para as crianças com SD, antes mesmo de elas 
conseguirem se expressar verbalmente. Assim, ações práticas possibilitam uma vida mais plena e independente da família, mas com relativo suporte.

Livros e blogs compõem diferentes tecnologias de comunicação que veiculam narrativas em que a ênfase é dada, respectivamente, ao relato escrito e ao relato multimodal, o qual pode incluir textos escritos, imagens fixas ou em movimento, sons, elementos das narrativas orais e, especialmente, interatividade.

Os livros escritos por pais de pessoas com SD tratam, em primeiro lugar, de registros de memória, feitos em tom confessional, como forma de elaborar o fato de se ter um filho com essa condição por meio do compartilhar da experiência, ou ainda de tornar pública a vida de alguém que tem SD, num processo de (re)delineamento e abertura do self (Foucault, 2003a). Em segundo lugar, sugerem imagens e carreiam significados relativos a uma condição geneticamente determinada pela presença de um cromossomo 21 extra e, mais amplamente, à genética e seus avanços tecnológicos.

Os weblogs ou apenas blogs despontaram nos anos 90 e constituem um nome genérico que compreende várias formas de interação acessadas via Internet, dentre elas os lifelogs, versão digital mais próxima dos antigos diários e que são aqui enfocados; os photoblogs, nos quais fotografias são adicionadas ao texto, que perde parte de sua importância; os linklogs, diferentes dos primeiros por permitir a postagem de links a outros websites sem a inclusão de detalhes da vida pessoal do indivíduo, ou blogueiro (blogger) na linguagem digital (Schaap, 2004). Blogs, mais do que ferramentas tecnológicas para preservar memórias visando a uma revisitação futura, voltam-se para o compartilhar de experiências ${ }^{3}$ não mais num âmbito privado restrito, mas direcionados a um público mais amplo, em grande medida anônimo, possibilitando a (re)construção do self por meio das experiências de outros (Van Dijck, 2007).

Por fim, o terceiro grupo de narrativas abarca reportagens sobre SD veiculadas entre janeiro de 2000 (ano em que o cromossomo 21 foi mapeado) e março de 2009 na revista semanal de maior circulação no país, Veja, publicada pela Editora Abril, e que aborda temas do cotidiano da 
sociedade brasileira, como política, economia, ciência, cultura e comportamento, e também temas mundiais, como guerras e conflitos diplomáticos; e no jornal $O$ Globo, de alcance nacional (apesar de sediado no Rio de Janeiro), que pertence às Organizações Globo. Tanto os leitores da Veja quanto os de $O$ Globo pertencem majoritariamente às classes $\mathrm{A}$ e $\mathrm{B}$, com escolaridade superior. As narrativas foram selecionadas pela busca on-line mediante a palavra-chave 'síndrome de Down', perfazendo um total de 158 ocorrências (48 na Veja e 110 em O Globo).

Com o intuito de apreender os sentidos e as imagens presentes nas narrativas escritas e iconográficas sobre SD em todas as suas sutilezas, priorizou-se o material implícito que é manifesto nos detalhes, nos gestos, nas reticências, nos silêncios, em detrimento do que é explícito, aparente. O interesse pelo indiciário ancora-se no modelo, de características semióticas, proposto pelo historiador Carlo Ginzburg (2001a, 2004), tendo por base o método desenvolvido pelo crítico de arte Giovanni Morelli, no século XIX, para identificar a verdadeira autoria de determinadas pinturas e diferenciá-las daquelas fraudulentas. Essa diferenciação se faria não em razão das características mais marcantes de determinado artista, concernentes a estilo ou escola, mas sim da sua marca autoral deixada na execução de pequenos e sutis detalhes, tais como dobras de tecido, orelhas, volteios dos cabelos, unhas.

O contato com o tema veiculado nas narrativas demandou uma atitude de 'estranhamento' (Ginzburg, 2001b), a fim de percebê-lo como se pela primeira vez, com distanciamento crítico, sem se deixar levar por interpretações e significados preestabelecidos e questionando tudo aquilo que se apresentava como 'natural' em relação à SD e às pessoas que com ela nascem.

A narrativa é um tipo de discurso que se define como figurativo por comportar personagens que realizam ações e por ser contextualizada espacial e temporalmente. O discurso organiza-se em dois níveis de profundidade, o das estruturas superficiais ou discursivas, que fala da maneira como a narrativa é contada, e o das estruturas profundas ou semionarrativas, que diz respeito ao sentido do que é contado. 
Consideraram-se como textos, e como tais passíveis de análise, as narrativas que se apresentaram como enunciados verbais (orais e escritos) ou não verbais (filmes, quadros, fotografias), com características de autonomia e dotados de significação e função integrais. Definir algo como um texto envolve a observação de determinados aspectos, como a coerência textual, que é aquilo que une as frases, no caso de textos verbais, ou os planos, no caso de textos imagéticos, caracterizando-os como partes de um todo mais abrangente. De acordo com a perspectiva do leitor/ouvinte, a coerência do texto diz respeito às competências textual e intertextual que permitem que ele, no caso da primeira, perceba as frases como fragmentos interligados de um todo, mesmo quando suas conexões estão implícitas, sendo capaz de supri-las quando necessário; e no caso da segunda, que possa lançar mão de experiências anteriores com outros textos para poder contextualizar o atual.

Estabelecidos os marcos referenciais, seguiram-se determinados procedimentos na análise do material coletado. Após a leitura exaustiva das narrativas, tanto escritas quanto iconográficas, encetou-se o exame comparativo de frases e enunciados, ou seja, das partes que compõem um texto, no sentido de identificar as categorias sêmicas presentes. As categorias sêmicas comportam semas e antissemas, entre os quais existe uma relação de disjunção, uma vez que eles são opostos, mas também de conjunção, pelo fato de pertencerem a uma mesma totalidade de sentido, um mesmo eixo semântico que os engloba.

A seguir, identificaram-se, dentre as categorias sêmicas, aquelas que se repetiam no texto, constituindo as categorias isotópicas. Por fim, distribuíram-se as categorias isotópicas encontradas em três níveis semânticos - o figurativo, o temático e o axiológico. O figurativo refere-se a significados apreendidos diretamente pelos sentidos, ligando-os à percepção do mundo real; o temático, a elementos abstratos que serão expressos pelos elementos figurativos (por exemplo: o cuidado é um elemento temático, enquanto o preparar o alimento para uma criança doente é figurativo); o terceiro nível, o axiológico, relaciona-se a algum sistema de valores que pode estar manifesto nos conteúdos do texto, e que valoriza 
eufórica ou disforicamente determinados conceitos (por exemplo, belo e feio, de acordo com um padrão).

Tais procedimentos constituem uma adaptação do método de leitura isotópica desenvolvido por Algirdas Julien Greimas (1987). O seu uso permite a passagem do que seria a significação que se encontra em cada frase ou enunciado tomado isoladamente, denominada microssemântica, para a busca da significação do discurso completo, observado em termos transfrasais, a macrossemântica.

A observação das categorias isotópicas produz uma grade de leitura que pode ser expressa graficamente por meio do quadrado semiótico, que resume a principal estrutura profunda de significação presente no texto completo. Aplica-se essa operação semiótica em algumas narrativas, como técnica analítica complementar, não para demarcar posições rígidas e literais, mas sim pela possibilidade de salientar a dinâmica de relação entre dois termos isotópicos numa determinada categoria e descortinar uma ampla gama de significados entre eles, transpondo uma oposição lógica binária. O arranjo dos termos no quadrado coloca-os sob tensão, de forma a sustentar ou não a hipótese que os posiciona num mesmo eixo semântico.

A produção de fatos científicos é um processo que envolve a construção de imagens e de elementos imaginativos que facilitam a circulação do conhecimento, por clarificar o que seriam conceitos abstratos (Van Dijck, 1998). As fronteiras entre os círculos biomédico e o não especializado são permeáveis, uma vez que ambos se encontram no âmbito da cultura, e as imagens e a imaginação tornam-se significativas porque mobilizam apelos com conteúdo dramático para tal grupo cultural.

A presença de uma condição genética espacializa e revela esse intrínseco e dinâmico entrelaçamento e solicita constantes movimentos de reconfiguração no sentido de incorporar conhecimentos, torná-los significativos e acomodá-los à perspectiva de vida de um indivíduo ou família específicos. Ao mesmo tempo, provoca reflexões sobre a responsabilidade envolvida e os possíveis desenlaces futuros. 
É possível acompanhar esses movimentos, uma vez que eles são plasmados nas narrativas produzidas individual ou coletivamente num espaço-tempo, descortinar imagens, elementos imaginativos e significados e compreender como foram apropriados, transformados, pronunciados e difundidos. É disso que trata a fuga que se apresenta a seguir.

NOTAS

1 Estas foram consultadas a fim de traçar o breve histórico do percurso científico das pesquisas sobre SD apresentado na 'Exposição', sem, entretanto, serem submetidas aos critérios analíticos aplicados às outras fontes.

2 Tal rede de apoio inclui associações locais criadas por pais de pessoas com SD, as quais oferecem contatos com outros pais, palestras e material informativo, agências de empregos, financiamento de concursos e premiações, residências onde vivem quatro ou cinco pessoas com algum tipo de deficiência acompanhadas de uma outra que administra a casa. Ao mesmo tempo, um ato governamental sobre adoção publicado em 1980, The Adoption Assistance and Child Welfare Act of 1980 (United States of America, 1980), passou a oferecer subsídios a pais que desejassem adotar uma criança, com valores adicionais caso fosse uma criança com alguma das deficiências listadas no ato, dentre as quais a SD. Diversas narrativas em blogs abordam processos de adoção, muitos dos quais em famílias nas quais já existe um membro com SD, e trazem links para organizações responsáveis por encontrar lares para essas crianças. Vários desses processos tornam-se possíveis graças a um extenso suporte também de particulares, feito por meio de doações.

3 Nesse sentido, observa-se uma certa volatilidade nos blogs, pois ao tentar reacessá-los, vários deles tinham mudado de nome ou haviam sido desativados, tornando impossível a sua relocalização. 